\title{
High-strength concrete eccentrically compressed elements
}

\author{
Anastasia Vasilenko ${ }^{1}$, Dmitry Chernogorsky ${ }^{1}$, Dmitry Strakhov ${ }^{1}$ and Leonid Sinyakov ${ }^{1}$ \\ ${ }^{1}$ Peter the Great St. Petersburg Polytechnic University, St. Petersburg, Russian Federation
}

\begin{abstract}
The article is devoted to the analysis of technical and economic efficiency of application of high-strength concrete (HSC) in the eccentrically compressed columns. In the first part of the paper, the effect of concrete grade on in-creasing the column stiffness depending on steel ratio at different values of the relative eccentricity is considered. According to the results of the calcu-lation, application of HSC is most effective at low values of the relative ec-centricity because increasing the concrete strength leads to more intensive increasing of column stiffness than increasing of steel ratio. In the second part of the paper, the material cost of the 1 linear meter of the column is cal-culated at the fixed value of column stiffness and application domain of HSC is defined in the case under consideration. In addition, load characteristics providing the efficiency of HSC application in the eccentrically compressed columns are determined.
\end{abstract}

\section{Introduction}

In accordance with ACI 363.2R-11 "Guide to quality control and assurance of high-strength concrete", high strength concrete (HSC) is defined as having a specified compressive strength more than $55 \mathrm{MPa}$ and mixed without the use polymeric additives and artificial aggregate. For the purpose of the European standards EN 1992-1-1 "Eurocode 2: Design of concrete structures. General rules and rules for buildings" and EN 206 "Concrete. Specification, performance, production and conformity", HSC shall be defined as having concrete strength grade $\mathrm{C} 50 / 60$ or greater, which corresponds to cube strength $60 \mathrm{MPa}$ and substantially correlates to the Russian codes and standards. This material has high processing and performance characteristics so that it is applied in sophisticated building projects [1-3]. Also the using of HSC in seismic areas and railway construction is widely investigated [4-5]. In addition, HSC is used in massive steel-reinforced concrete structures [6]

Modern developments in chemization of concrete mixtures [7-9] provide to obtain HSC with wide range properties that determine application domain of this material. Primary benefits of HSC are high strength, low creep and shrinkage, durability, fastness to staining, low water and gas permeability $[8,10]$.

A large number of research papers is concerned with the investigating of HSC and its properties. Much attention is given to investigating the behavior of reinforced concrete columns under various loads. The study [11] represents the investigation of high- performance concrete (HPC) as well as highperformance steel fibre reinforced concrete (HPSFRC) elements in multi-storey building. It was discovered that it is more rational to use HPSFRC than HPC if column spacing is more than $8 \mathrm{~m}$ in the first eight floors of building. Umesh K. Sharma, Z. Huang, R. Kliukas and etc. investigated HSC columns under axial compression [12-14]. In addition, substantial progress has been made in studying the behavior of concrete columns under eccentric loading $[2,15]$. Analytical and experimental researches [2, 3, 16-24] confirm feasibility of using HSC in eccentrically compressed elements. It is worth mentioning that the load capacity of eccentrically compressed column increases as longitudinal steel ratio increases, and use of small longitudinal steel bar diameter in HSC eccentrically compressed columns is not efficient $[2,20]$. Investigating of using high strength steel in HSC columns under eccentric loading is also promising direction [25].

Despite the results of the conducted researches [2628], HSC is not widely distributed in Russia. The economic and technological effectivity of replacing traditional concrete with modified concrete is questioned. Based on the trends of international scientific research, it is necessary to establish the general recommendations concerning the using HSC eccentrically compressed load-carrying structural elements.

The purpose of this research is to determine the efficiency of using HSC in eccentrically compressed 
load-carrying structural elements (columns) and its application domain.

\section{Methods}

It is widely known that the stability (buckling prevention) of the eccentrically compressed columns depends on their stiffness $D$, which can be determined by the following formula:

$$
D=k_{b} \times E_{b} \times I+k_{s} \times E_{s} \times I_{s},
$$

where $E_{b}, E_{s}$ - are concrete and reinforcement modules of elasticity respectively;

$-I, I_{s}$ - are moments of inertia of concrete and all longitudinal reinforcement cross-sectional areas respectively, relative to the axis passing through the cross sectional center of gravity;

$k_{s}=0.7$.

$$
k_{b}=\frac{0.15}{\varphi_{l} \times\left(0.3+\delta_{e}\right)},
$$

where $\varphi_{l}-$ is an coefficient, taking into account the influence of the load duration. In the calculations, the authors accept the option without short-term loads. Thus, all loads are long-acting and $\varphi_{l}=2$;

$\delta_{e}-$ is a relative value of axial force eccentricity $\frac{e_{0}}{h}$, accepted not less than 0.15 and not more than 1.50 .

For rectangular elements with double reinforcement, the formula for stiffness $D$ calculating can be reduced to:

$$
D=E_{b} b h^{3} \times\left[\frac{0.0125}{\varphi_{l} \times\left(0.3+\delta_{e}\right)}+0.175 \times \mu \alpha \times\left(\frac{h_{0}-a^{\prime}}{h}\right)^{2}\right],
$$

where $\mu$ - steel ratio;

$h$ - depth of a cross section;

$h_{0}$ - effective depth of a cross section;

$\alpha$ ' - distance from the compressed reinforcement center to the column cross section edge.

$$
\alpha=\frac{E_{s}}{E_{b}}
$$

The stiffness of the element $D$ (and, consequently, the stability) increases under changing the concrete grade and the ultimate cost of 1 linear meter of the structure were selected as assessment criteria for evaluating the effectiveness of HSC use in the eccentrically compressed elements (columns).

The cost of 1 cubic meter of a concrete and 1 ton of reinforcement was assigned directively based on the market analysis. The calculations were performed on the example of market prices for steel and concrete ratio in the conditions of the Russian Federation ( 1 ruble is equal to 0.014 euros at the exchange rate for November 2019). The methodology of the calculations is quite universal, and their results can be used in countries with a similar ratio of market prices for steel and concrete.

\section{Results and Discussion}

\subsection{Calculation of the reinforced concrete column stiffness at various values of the relative eccentricity $\delta e$}

In the first part of the work, the stiffness of reinforced concrete columns $D$ with different steel ratios was calculated for the values of the relative eccentricity of the load application $\delta_{e}=0.15, \delta_{e}=1.50$ and the dependence of the cost change depending on the stiffness value for concrete grades B20, B60, B80 was analyzed.

The elements have the same cross-sectional dimensions $\left(b=30 \mathrm{~cm}, h=60 \mathrm{~cm}, h_{0}=55 \mathrm{~cm}\right)$, the reinforcement of class A400 with a c of $R_{s}=355 \mathrm{MPa}$ is adopted. The calculated values of reinforcement area $A_{s, t o t}$ are taken based on the elements steel ratio $\mu$. Data about the columns design is given in Table 1.

Table 1. Reinforcement of the elements.

\begin{tabular}{|c|c|c|c|c|c|c|c|c|c|c|c|}
\hline $\begin{array}{c}\boldsymbol{\mu} \boldsymbol{\%} \\
\mathbf{\%}\end{array}$ & $\mathbf{0 . 0}$ & $\mathbf{0 . 5}$ & $\mathbf{1 . 0}$ & $\mathbf{1 . 5}$ & $\mathbf{2 . 0}$ & $\mathbf{2 . 5}$ & $\mathbf{3 . 0}$ & $\mathbf{3 . 5}$ & $\mathbf{4 . 0}$ & $\mathbf{4 . 5}$ & $\mathbf{5 . 0}$ \\
\hline $\begin{array}{c}A_{s, t o t} \\
\mathrm{~cm}^{2}\end{array}$ & 0.0 & 9.0 & 18.0 & 27.0 & 36.0 & 45.0 & 54.0 & 63.0 & 72.0 & 81.0 & 90.0 \\
\hline $\begin{array}{c}A, \\
\mathrm{~cm}^{2}\end{array}$ & 1800 & 1791 & 1782 & 1773 & 1764 & 1755 & 1746 & 1737 & 1728 & 1719 & 1710 \\
\hline
\end{tabular}

The results of calculating the column stiffness $D$ for

\begin{tabular}{|c|c|c|c|c|c|c|c|c|c|c|c|}
\hline \multirow{2}{*}{$\begin{array}{c}\text { Concrete } \\
\text { grade }\end{array}$} & \multicolumn{11}{|c|}{$D$ at $\delta_{e}=0.15, \mathrm{kN} \times \mathrm{m}^{2}, 10^{3}$ at $\mu$, equal to $\%$} \\
\hline & 0.00 & 0.50 & 1.00 & 1.50 & 2.00 & 2.50 & 3.00 & 3.50 & 4.00 & 4.50 & 5.00 \\
\hline B20 & 24.75 & 33.02 & 41.29 & 49.56 & 57.83 & 66.09 & 74.36 & 82.63 & 90.90 & 99.17 & 107.44 \\
\hline B60 & 35.55 & 43.82 & 52.09 & 60.36 & 68.63 & 76.89 & 85.16 & 93.43 & 101.7 & 109.97 & 118.24 \\
\hline B80 & 37.80 & 46.07 & 54.34 & 62.61 & 70.88 & 79.14 & 87.41 & 95.68 & 103.9 & 112.22 & 120.49 \\
\hline
\end{tabular}
various values of the relative eccentricity $\delta_{e}$ are presented in Tables 2 ad 3 .

\begin{tabular}{|c|c|c|c|c|c|c|c|c|c|c|c|}
\hline \multirow{2}{*}{$\begin{array}{l}\text { Concrete } \\
\text { grade }\end{array}$} & \multicolumn{11}{|c|}{$D$ at $\delta_{e}=1.50, \mathrm{kN} \times \mathrm{m}^{2}, 10^{3}$ at $\mu$, equal to $\%$} \\
\hline & $\mathbf{0 . 0 0}$ & $\mathbf{0 . 5 0}$ & 1.00 & 1.50 & 2.00 & 2.50 & $\mathbf{3 . 0 0}$ & 3.50 & 4.00 & 4.50 & 5.00 \\
\hline B20 & 6.19 & 14.46 & 22.73 & 30.99 & 39.26 & 47.53 & 55.80 & 64.07 & 72.34 & 80.61 & 88.88 \\
\hline
\end{tabular}

Table 2. Stiffness values of an element for concrete grades B20, B60 and B80 depending on steel ratio $\mu$ at $\delta_{e}=0.15$.

Table 3. Stiffness values of an element for concrete grades B20, B60 and $\mathrm{B} 80$ depending on steel ratio $\mu$ at $\delta_{e}=1.50$. 


\begin{tabular}{|l|l|l|l|l|l|l|l|l|l|l|l|}
\hline B60 & 8.89 & 17.16 & 25.43 & 33.69 & 41.96 & 50.23 & 58.50 & 66.77 & 75.04 & 83.31 & 91.58 \\
\hline B80 & 9.45 & 17.72 & 25.99 & 34.26 & 42.53 & 50.79 & 59.06 & 67.33 & 75.60 & 83.87 & 92.14 \\
\hline
\end{tabular}

To calculate the cost of 1 linear meter of the structure the authors use the analysis of the concrete market in St. Petersburg. The calculation results are given in Tables 4 and 5.

Table 4. Concrete price, rub.

\begin{tabular}{|c|c|c|c|}
\hline Concrete grade & Unit of measure & Mass, $\mathbf{k g}$ & $\begin{array}{c}\text { Price excluding VAT. } \\
\text { Current estimated } \\
\text { price per } \mathbf{~ m}^{\mathbf{3}}, \mathbf{r u b} .\end{array}$ \\
\hline B20 & $\mathrm{m}^{3}$ & 2450 & 3812.93 \\
\hline B60 & $\mathrm{m}^{3}$ & 2450 & 5429.14 \\
\hline B80 & $\mathrm{m}^{3}$ & 2450 & 5700.00 \\
\hline
\end{tabular}

Cost of 1 ton of class A400 reinforcement was averaged and amounts to 38310 rubles.

Reinforcement mass per 1 linear meter of the structure was calculated based on the received values of As, tot for various coefficients of the steel ratio and the steel density equal to $7.85 \times 103 \mathrm{~kg} / \mathrm{m} 3$.

Table 5. Price of 1 linear meter of the construction for concrete grades B20, B60 and B80 under various steel ratios, rub.

\begin{tabular}{|c|c|c|c|c|c|}
\hline $\begin{array}{c}\text { Concrete } \\
\text { grade }\end{array}$ & $A, \mathrm{~cm}^{2}$ & $\begin{array}{l}A_{\mathrm{s}, t o t}, \\
\mathbf{c m}^{2}\end{array}$ & $\begin{array}{l}\mu, \\
\%\end{array}$ & $\begin{array}{c}\text { Mass of } \\
\text { reinforcement } \\
\text { per } 1 \text { linear } \\
\text { meter, } t\end{array}$ & 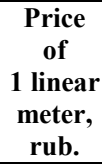 \\
\hline \multirow{6}{*}{ B20 } & 1800.00 & 0.00 & 0.00 & 0.0000 & 686.33 \\
\hline & 1782.00 & 18.00 & 1.00 & 0.0141 & 1220.79 \\
\hline & 1764.00 & 36.00 & 2.00 & 0.0283 & 1755.25 \\
\hline & 1746.00 & 54.00 & 3.00 & 0.0424 & 2289.70 \\
\hline & 1728.00 & 72.00 & 4.00 & 0.0565 & 2824.16 \\
\hline & 1710.00 & 90.00 & 5.00 & 0.0707 & 3358.62 \\
\hline \multirow{6}{*}{ B60 } & 1800.00 & 0.00 & 0.00 & 0.0000 & 977.25 \\
\hline & 1782.00 & 18.00 & 1.00 & 0.0141 & 1508.79 \\
\hline & 1764.00 & 36.00 & 2.00 & 0.0283 & 2040.34 \\
\hline & 1746.00 & 54.00 & 3.00 & 0.0424 & 2571.89 \\
\hline & 1728.00 & 72.00 & 4.00 & 0.0565 & 3103.44 \\
\hline & 1710.00 & 90.00 & 5.00 & 0.0707 & 3634.99 \\
\hline \multirow{5}{*}{ B80 } & 1800.00 & 0.00 & 0.00 & 0.0000 & 1026.00 \\
\hline & 1782.00 & 18.00 & 1.00 & 0.0141 & 1557.06 \\
\hline & 1764.00 & 36.00 & 2.00 & 0.0283 & 2088.12 \\
\hline & 1746.00 & 54.00 & 3.00 & 0.0424 & 2619.19 \\
\hline & 1728.00 & 72.00 & 4.00 & 0.0565 & 3150.25 \\
\hline B80 & 1710.00 & 90.00 & 5.00 & 0.0707 & 3681.31 \\
\hline
\end{tabular}

Based on the received results, it is possible to construct a cost-stiffness dependence diagram for various values of the relative eccentricity (Fig. 2).

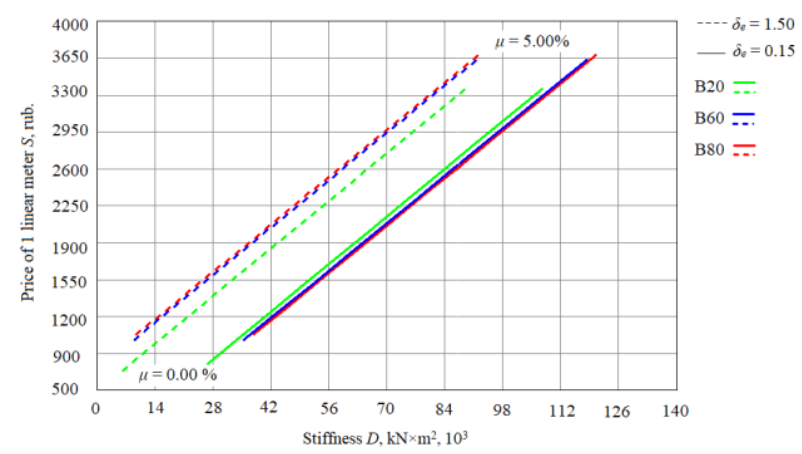

Fig. 1. Cost-stiffness dependence diagram for two values of the relative eccentricity $\delta_{e}=0.15$ and $\delta_{e}=1.50$.

As it can be seen from the diagram in Fig. 2, with a large value of the relative eccentricity $\delta_{e}=1.50$ and with the same value of stiffness, the cost of 1 linear meter of the structure made of concrete grade B60 and B80 is significantly higher in comparison with the structure made of concrete grade B20. The diagram lines at $\delta_{e}=$ 0.15 are nearly identical. However, it is clear that a structure of concrete grade B20 is more expensive than a similar structure of concrete grade B60 and B80.

The diagram in Fig. 2 clearly illustrates that the use of HSC is rational for small values of relative eccentricity $\delta_{e}$.

For a more detailed analysis, it is necessary to consider separately the influence of the concrete grade and the steel ratio on the structural stiffness increase at different values of relative eccentricity $\delta_{e}$ (Fig. $3-$ Fig. 4).

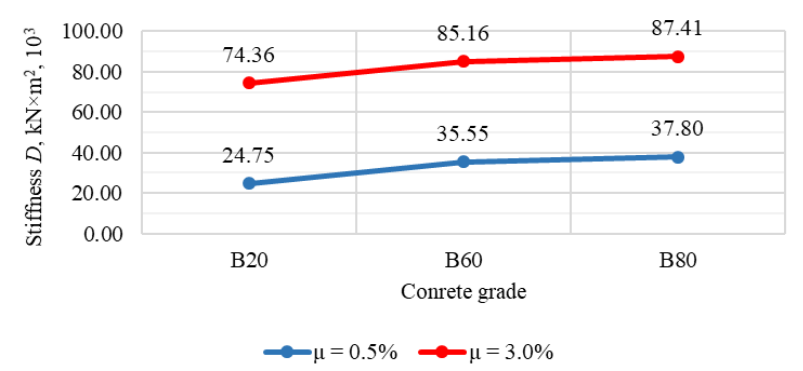

Fig. 2.Stiffness-concrete grade dependence diagram for the value of relative eccentricity $\delta_{e}=0.15$.

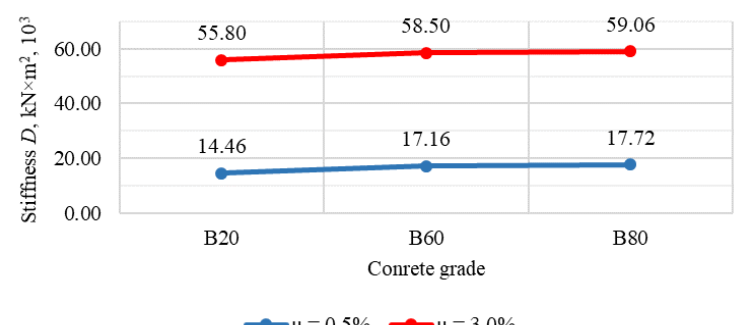

Fig. 3. Stiffness-concrete grade dependence diagram for the value of relative eccentricity $\delta_{e}=1.50$. 
According to the data given in Fig. 3 and Fig. 4, in order to increase the structure's stiffness, increasing the concrete grade at low values of steel ratio is more effective than at large values. This effect is the most pronounced for small values of relative eccentricity.

For $\mu=0.5 \%$, the structure's stiffness increased by 1.53 and 1.23 times with $\delta_{e}=0.15$ and $\delta_{e}=1.50$, respectively. With $\mu=3.0 \%$, these values account for 1.18 and 1.06 , respectively.

Stiffness-steel ratio dependence diagrams for various concrete grades are presented in Fig. 5 and Fig. 6.

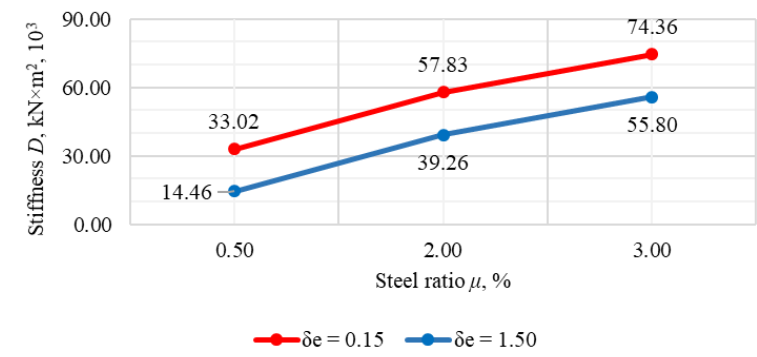

Fig. 4. Stiffness-steel ratio dependence diagram for concrete grade B20.

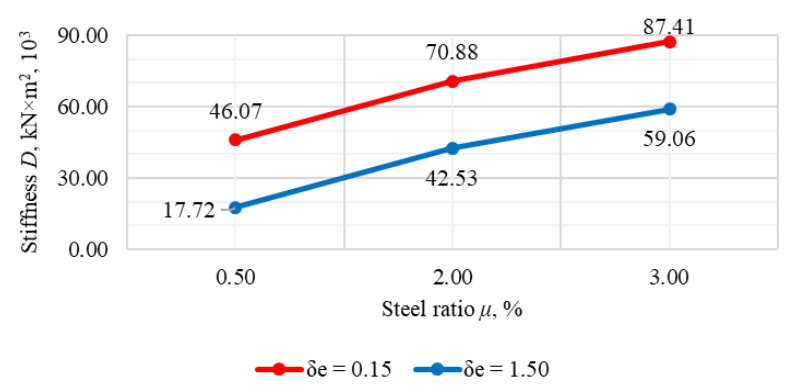

Fig. 5. Stiffness-steel ratio dependence diagram for concrete grade B80.

Fig. 5 and Fig. 6 show that the steel ratio has a stronger effect on the change in structural stiffness at high eccentricities. Moreover, for a structure made of concrete grade B20, this influence is much greater than for a similar structure made of concrete grade B 80 .

For concrete grade B20, an increase in the steel ratio $\mu$ leads to an increase in stiffness of 2.25 and 3.86 times with $\delta_{e}=0.15$ and $\delta_{e}=1.50$, respectively. For a structure of concrete grade B80, these values are 1.90 and 3.33, respectively.

Attained results correlate well with analytical and experimental researches $[2,20,26-28]$. The load capacity (and, consequently, the stability) of the eccentrically compressed column increases as longitudinal steel ratio increases $[2,20]$.

\subsection{Determining the applicable scope of HSC within the addressed goal}

In the second part of the research paper, the applicability limits of HSC were determined under conditions of a specific task. The material costs of 1 linear meter of the column structure with stiffness $D=47500 \mathrm{kN} \times \mathrm{m}^{2}$ for concrete grades B20, B60, B80 under various values of relative eccentricity $\delta_{e}$ were chosen as the initial parameter. Cost calculation results are given in Table 6 .

Table 6. Calculation data of the costs.

\begin{tabular}{|c|c|c|c|c|c|c|c|c|c|c|}
\hline$\delta_{e}$ & $\begin{array}{c}\text { Concrete } \\
\text { grade }\end{array}$ & $\mathrm{D}, \mathrm{kN} \mathrm{m}^{2}$ & $\mathbf{D}_{\mathrm{b}}, \mathbf{k N} \mathbf{m}^{2}$ & $\mathrm{D}_{\mathrm{s}}, \mathrm{kN} \mathrm{m}^{2}$ & $\mu, \%$ & $A_{s}, \mathbf{c m}^{2}$ & $A_{b}, \mathbf{c m}^{2}$ & $S_{b}$, rub. & $\mathrm{S}_{\mathrm{s}}$, rub. & S, rub. \\
\hline \multirow{3}{*}{0.15} & B20 & 47500.00 & 24750.00 & 22750.00 & 1.38 & 24.76 & 1775.24 & 676.89 & 744.68 & 1421.56 \\
\hline & B60 & 47500.00 & 35550.00 & 11950.00 & 0.72 & 13.01 & 1786.99 & 970.18 & 391.16 & 1361.34 \\
\hline & B80 & 47500.00 & 37800.00 & 9700.00 & 0.59 & 10.56 & 1789.44 & 1019.98 & 317.51 & 1337.49 \\
\hline \multirow{3}{*}{0.30} & $\mathrm{~B} 20$ & 47500.00 & 18562.50 & 28937.50 & 1.75 & 31.50 & 1768.50 & 674.32 & 947.21 & 1621.53 \\
\hline & B60 & 47500.00 & 26662.50 & 20837.50 & 1.26 & 22.68 & 1777.32 & 964.93 & 682.07 & 1647.01 \\
\hline & B80 & 47500.00 & 28350.00 & 19150.00 & 1.16 & 20.84 & 1779.16 & 1014.12 & 626.84 & 1640.96 \\
\hline \multirow{3}{*}{0.75} & $\mathrm{~B} 20$ & 47500.00 & 10607.14 & 36892.86 & 2.23 & 40.16 & 1759.84 & 671.02 & 1207.61 & 1878.63 \\
\hline & B60 & 47500.00 & 15235.71 & 32264.29 & 1.95 & 35.12 & 1764.88 & 958.18 & 1056.11 & 2014.29 \\
\hline & B80 & 47500.00 & 16200.00 & 31300.00 & 1.89 & 34.07 & 1765.93 & 1006.58 & 1024.54 & 2031.12 \\
\hline \multirow{3}{*}{1.50} & $\mathrm{~B} 20$ & 47500.00 & 6187.50 & 41312.50 & 2.50 & 44.97 & 1755.03 & 669.18 & 1352.28 & 2021.46 \\
\hline & B60 & 47500.00 & 8887.50 & 38612.50 & 2.33 & 42.03 & 1757.97 & 954.43 & 1263.90 & 2218.33 \\
\hline & B80 & 47500.00 & 9450.00 & 38050.00 & 2.30 & 41.41 & 1758.59 & 1002.39 & 1245.49 & 2247.88 \\
\hline
\end{tabular}


According to the data in Table 7, for small eccentricities $\left(\delta_{e}=0.15\right)$, to obtain the same stiffness, a greater difference in the amount of reinforcement and its cost is required than for large eccentricities $\left(\delta_{e}=1.50\right)$. Therefore, for small eccentricities, the difference module in cost of high-strength and ordinary concrete is less than the difference module in cost of the required amount of reinforcement. For large eccentricities, the situation appears to be opposite.

Graphical interpretation of the Table data is shown in Fig. 7.

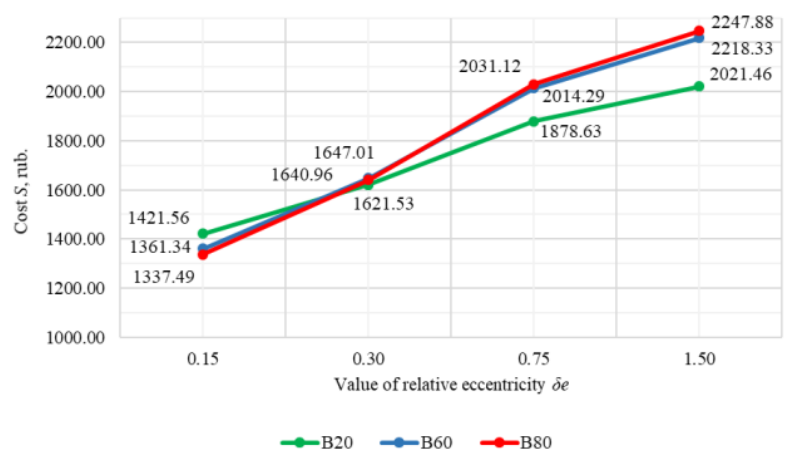

Fig. 6. Cost-relative eccentricity dependence diagram for various concrete grades.

As is evident from the diagram in Fig. 7 and the data from Table 7, the use of HSC of class B60 is beneficial with relative eccentricities not exceeding the value $\delta_{e} \approx$ 0.25 . For concrete grade B80, this boundary is slightly higher and amounts to $\delta_{e} \approx 0.27$.

Obtained results partly correspond to conclusions obtained in works [26-28], where using HSC is considered more effective when the value of relative eccentricity is less then accidental eccentricity [26].

\section{Conclusions}

Based on the conducted studies, the following key findings have been presented:

1. Stiffness of a construction and therefore its stability increase more intensively with small steel ratio values $(\mu=0.5 \%)$ in comparison with high values $(\mu=$ $3.0 \%$ ). This tendency is more pronounced at the low values of eccentricity.

2. At high values of eccentricity ratio $\left(\delta_{e}=1.50\right)$ to ensure the equal stability of compressed elements, the use of high-strength concrete is not cost-effective, since the amount of required reinforcement, which is a key factor determining the stiffness of the structure (and, therefore, the cost of materials), is practically independent of the concrete grade.

3 . With small relative eccentricities $\left(\delta_{e}=0.15\right)$, the use of high-strength concrete $(\mathrm{B} 60, \mathrm{~B} 80)$ can provide some reduction in the total cost of the construction materials, because with small eccentricities, an increase in the concrete grade leads to a more intensive increase in stiffness in comparison with steel ratio.

4. The application field of high-strength concrete within the current task is limited by relative eccentricities, not exceeding the value $\delta_{e} \approx 0.25$ for concrete grade $\mathrm{B} 60$ and $\delta_{e} \approx 0.27$ for concrete grade $\mathrm{B} 80$.

5. Despite of the fact that the above-mentioned numerical values are of a private nature, since the effectiveness of using high-strength concrete also depends on the size of the structure, market price ratios in different regions, etc., the guidelines regarding the influence of the relative eccentricity values on the application field of high-strength concrete are quite universal.

6. However, as concrete grade increases, strength increases faster than the modulus of elasticity, which determines the stiffness of the column. Therefore, a promising research area is the effect of concrete grade increasing on the strength of the columns.

\section{References}

1.ACI 363.2R-11: Guide to Quality Control and Assurance of High-Strength Concrete, 19 (2011)

2.BS EN 1992-1-1:2004 Eurocode 2. Design of concrete structures, 227 (2011)

3.EN 206-1. Concrete - Part 1: Specification, performance, production and conformity, 41 (2013)

4.GOST 31914-2012 High-strength heavy and fine concretes for monolithic constructions. Rules for quality control and assessment, 15 (2012)

5. Code of practice 63.13330.2012 Concrete and reinforced concrete structures. The main provisions. Updated edition of Construction Standards and Regulations 52-01-2003, 434 (2012)

6. Code of practice 311.1325800.2017 Concrete and reinforced concrete structures from high strength concrete. Design rules, 27 (2017)

7.R. Drzymała, T., Jackiewicz-Rek, W., Gałaj, J., \& Šukys, J. Civ. Eng. Manag. 24, 138-144 (2018) DOI: $10.3846 /$ jcem.2018.457

8.H. A. Kottb, N. F. El-Shafey, and A. A. Torkey, HBRC J. 11, 22-34 (2015) DOI: 10.1016/j.hbrcj.2014.02.006

9. R. Golov, V. DIkareva, R. Gorshkov, and A. Agarkov, E3S Web Conf. 33, 6 (2018) DOI: $10.1051 / \mathrm{e} 3$ sconf/20183303033

10. J. Davari, M. Jazayeri Moghdas, J Fundam Appl Sci. 8, 532-546 (2016) DOI: 10.4314/jfas.8vi2s.35

11. O. Smirnova, Procedia Eng. 172, 10391043 (2017) DOI: 10.1016/j.proeng.2017.02.158

12. D. Benamara, B. Mezghiche, and M. F. Zohra, Phys. Procedia 55, 342-347 (2014) DOI: 10.1016/j.phpro.2014.07.050

13. N.I. Vatin, YU.G. Barabanshchikov, M.V. Komarinskiy, Mag. Civ. Eng. 56(4), 3-10 (2015) DOI: 10.5862/MCE.56.1

14. A. Alsalman, C. N. Dang, G. S. Prinz, and W. M. Hale, Constr. Build. Mater. 153, 918-928 (2017) DOI: 10.1016/j.conbuildmat.2017.07.158

15. U. K. Sharma, P. Bhargava, and S. K. Kaushik, J. Adv. Concr. Technol. 3, 267-281 1. (2005) DOI: $10.3151 /$ jact.3.267 
16. Z. Huang, X. Huang, W. Li, Y. Zhou, L. Sui, and J. Y. R. Liew, 323-329 (2018) DOI: 10.4995/ASCCS2018.2018.7034

17. R. Kliukas, A. Kudzys, and R. Vadluga, J. Civ. Eng. Manag. 16, 189-196 (2010) DOI: $10.3846 /$ jcem.2010.20

18. I.N. Starishko, Vestn. MGSU [Proceedings Moscow State Univ. Civ. Eng]. 3, 107-116 (2014) DOI: 10.22227/1997-0935.2014.3.107-116

19. A. F. Pour, A. Gholampour, J. Zheng, and T. Ozbakkaloglu, IOP Conf. Ser. Mater. Sci. Eng. 301, 6 (2018) DOI: 10.1088/1757-899X/301/1/012058

20. J. Qian, Y. Zhang, W. Zhang, J. Tsinghua Univ. Technol. 55, 1-7 (2015)

21. D. R. C. de Oliveira, I. I. R. Damasceno, V. H. L. Branco, Rev. ALCONPAT 8, 150-162 (2018) DOI: $10.21041 /$ ra.v8i2.276

22. J. H. Lee and H. S. Son, ACI Struct. J. 97, 75-85 (2000)

23. Kardasz, J. Doskocz, M. Hejduk, P. Wiejkut, and H. Zarzycki, J. Civ. Environ. Eng. 8, 308 (2016) DOI: $10.4172 / 2165-784 X .1000308$

24. S. A. Kristiawan, A. Supriyadi, S. Sangadji, T. Anggraeni, and M. M. Pattiwael, Int. J. Adv. Struct. Eng. 11, 31-43 (2019) DOI: 10.1007/s40091-019-0214-8

25. W. P. Lokuge, S. Setunge, and J. G. Sanjayan, Mag. Concr. Res. 55, 331-341 (2003) DOI: $10.1680 /$ macr.2003.55.4.331

26. M. N. S. Hadi and H. Zhao, J. Mater. Civ. En g. 23, 823-832 (2011) DOI: 10.1061/(ASCE)MT.19435533.0000234

27. M. Elsayed, M. Elassaly, and W. Esmail, Int. Res. J. Eng. Technol. 5, 1336-1343 (2018)

28. Y. Hou, S. Cao, X. Ni, Y. Li, Materials 12(13), 2139 (2019) DOI: 10.3390/ma12132139

29. N. N. Trekin and E. N. Kodysh, Vestn. MGSU [Proceedings Moscow State Univ. Civ. Eng.] 2, 39-43 (2011)

30. A.I. Bedov, V.V. Babkov, A.I. Gabitov, A.S Salov, Vestn. MGSU [Proceedings Moscow State Univ. Civ. Eng.] 8, 76-84 (2012) DOI: 10.22227/19970935.2012.8.76-84

31. Il.T. Mirsayapov, A.I. Fattakhova, Izv. KSUAE 4(42), 182-188 (2017)

32. S.V. Ivleva, E.Yu. Malov, E.V Bykovskaya, Territorialnyj sbornik smetnyh tsen na materialy, izdeliya i konstruktsii, primenyaemye $\mathrm{v}$ stroitelstve. Sankt-peterburg. (TSSC - 2001), 11(83) (2018) 